\title{
The Impact of Self-Esteem, Academic Self-Efficacy and Perceived Stress on Academic Performance: A Cross-Sectional Study of Saudi Psychology Students
}

Mohsen Alyami (MHlthSc, BHlthSc (Psych))

School of Psychology, Massey University, Auckland, New Zealand Zeyad Melyani (PhD)

Assistant Professor, Head of Department of Psychology, Faculty of Arts and Humanities, King Abdulaziz University, Jeddah, Saudi Arabia

\section{Abdullrahman Al Johani (PhD)}

Professor of Health Psychology, Department of Psychology, College of Education, Taif University, Taif, Saudi Arabia

\section{Ehsan Ullah (M.B.,B.S., M.Phil, FRS Public Health)}

Clinical Effectiveness Advisor, Quality Department, Auckland District Health Board, Auckland, New Zealand

\section{Hussain Alyami (MBChB)}

Consult Liaison Psychiatry, Starship Hospital, Auckland District Health Board, New Zealand and South Auckland Clinical Campus, The University of Auckland, Auckland, New Zealand

\section{Frederick Sundram (PhD; MSc; MA; FRCPsych(UK); MBChB)}

Department of Psychological Medicine, Faculty of Medical and Health

Sciences, The University of Auckland, Auckland, New Zealand

$$
\text { Andrew Hill (MBChB, MD, EdD, FRACS) }
$$

Department of Surgery, South Auckland Clinical Campus, Faculty of Medical and Health Sciences, The University of Auckland, Auckland, New Zealand

\section{Marcus Henning (PhD, MA, MBus)}

Centre of Medical and Health Sciences Education, The University of Auckland, Auckland, New Zealand 


\section{Abstract}

Self-esteem, academic self-efficacy, perceived stress, and preferred learning styles have been linked to academic performance. Investigation of the relationships between these variables has mainly occurred with medical and dental tertiary students in Saudi Arabia, but no previous study has focused on psychology students. The main purpose of the current study was to assess stress levels and preferred learning styles, and examine the relationships between self-esteem, academic self-efficacy, perceived stress, and academic performance among a cohort of psychology students in Saudi Arabia. Participants were 214 psychology students from Taif University and King Abdulaziz University, who completed online measures including the VARK, the Perceived Stress Scale (PSS), the Academic Self-Efficacy (ASE), and the Rosenberg Self-Esteem Scale (RSES). Prevalence of stress was overwhelming, with $71 \%$ being highly stressed (PSS $\geq 27-40$ ). Most of the sample preferred a multimodal learning style. Furthermore, low yet significant correlations between academic performance and academic self-efficacy, $\mathrm{r}_{\mathrm{s}}(212)=.188, \mathrm{p}=.003$, and self-esteem, $\mathrm{r}_{\mathrm{s}}(212)=.121, \mathrm{p}=.039$, were identified. However, academic performance was not correlated with perceived stress levels.

Keywords: Self-esteem; self-efficacy; stress; academic performance.

\section{Introduction}

Understanding the effects of psychological factors on academic performance is of great importance and the literature has extensively investigated the role of self-esteem (Cardoso, Ferreira, Abrantes, Seabra, \& Costa, 2011; Rosli et al., 2012), self-efficacy (Cayubit, 2014; Khan, Cansever, Avsar, \& Acemoglu, 2013), stress (Hamdan-Mansour \& Dawani, 2008; Zajacova, Lynch, \& Espenshade, 2005), and preferred learning styles (Abdallah, Al-zalabani, \& Alqabshawi, 2013; Almigbal, 2015).

Self-esteem and self-efficacy, although related, are separate constructs. While self-esteem is defined as "a favorable or unfavorable attitude toward the self" (Rosenberg, 1965), self-efficacy is related to the person's confidence in preforming a specific task (Bandura, 1977). In the learning domain, both concepts have been linked to academic performance (Fathi-Ashtiani, Ejei, Khodapanahi, \& Tarkhorani, 2007; Pullmann \& Allik, 2008; Turner, Chandler, \& Heffer, 2009; T. Williams \& Williams, 2010). In the United Arab Emirates, Afari and colleagues (2012) examined the relationship between selfesteem and academic performance in 225 college students and found a significant positive correlation, suggesting high self-esteem is associated with high academic achievement. Also, the links between academic self-efficacy 
and academic performance are well established (Al-Harthy \& Was, 2013; Khan, 2013; Turner et al., 2009; Williams \& Williams, 2010), and this research affirms that high levels of self-efficacy are related to higher levels of academic achievement.

There is considerable evidence that shows that high levels of stress results in undesirable outcomes, including poor memory and concentration, which lead to ineffective learning and poor academic performance (Aboalshamat, Hou, \& Strodl, 2015; Goff, 2011; Hamdan-Mansour \& Dawani, 2008). High levels of stress are also associated with reduced selfesteem among college students (Edwards, Burnard, Bennett, \& Hebden, 2010). Another educational domain that has been proposed to potentially influence learning is student learning style. Learning styles are defined as "the composite of cognitive, affective, and psychological factors that serve as relatively stable indicators of how a learner perceive, interacts with, and responds to the learning environment" (Keefe, 1989). It has been argued that matching teaching methods with students' preferred learning styles can facilitate learning (Keefe, 1989; Sadler-Smith \& Smith, 2004). However, there is evidence that contradicts this claim (Rohrer \& Pashler, 2012; Urval et al., 2014; Zacharis, 2011).

There is a well-established theoretical framework that can be used to establish hypothesized relationships between self-esteem, self-efficacy, stress, and academic performance. Bandura's Social Cognitive Theory (Bandura, 1991) suggests that personal, environmental, and behavioral factors have a continuous mutual influence over each other, which is termed triadic reciprocality (Bandura, 1991). In reference to the Social Cognitive Theory, Schunk (1999) explained that personal variables may include attributions and self-efficacy, among others. According to Bandura's model, environmental variables refer to social influences such as feedback and instructions from external sources. In addition, behavioral variables refer to the achievement outcomes such as learning, motivation, and performance. In the present study, self-esteem and self-efficacy represent personal variables, learning styles and stress represent environmental factors, and academic performance represents behavioral variables.

In Saudi Arabia, only a few studies have examined the impact of the aforementioned variables on academic achievement. For example, researchers have examined the relationship between stress and academic performance in dental (Al-Sowygh, 2013) and medical (Abdulghani, AlKanhal, Mahmoud, Ponnamperuma, \& Alfaris, 2011) students at King Saud University, the largest university in Saudi Arabia. Other researchers have investigated the impact of self-esteem (among other psychological variables such as achievement motivation and satisfaction with life) on academic performance among health sciences students (Hamaideh \& Hamdan-Mansour, 2014). 
To the best of our knowledge, there are no previous studies investigating the relationships between self-esteem, academic self-efficacy, stress and academic performance among psychology students in Saudi Arabia. Therefore, this study is aimed at (a) measuring stress levels, self-efficacy, selfesteem, and assessing preferred learning styles and (b) examining the effects of these psychological variables on academic performance among psychology students in Saudi Arabia.

\section{Methods:}

\section{Study design and participants}

A correlational cross-sectional study design was employed. The target population was exclusively male psychology students in two universities: Taif University $(n=100)$ and King Abdulaziz University $(n=190)$. Convenience sampling was employed.

\section{Study setting}

Taif University, located in the city of Taif in the Southwest Province of Saudi Arabia, was established in 2003. The Department of Psychology offers a 4-year Bachelor program in industrial/organizational psychology, health psychology, and educational psychology. It also offers a Master degree in educational psychology. King Abdulaziz University, situated in Jeddah, was established in 1967. The Department of Psychology also offers a 4-year Bachelor degree, mainly in general psychology, while the Masters programs are in criminal psychology and counseling psychology. Both universities have separate campuses for males and females. The language of instruction is Arabic.

\section{Procedure}

Ethics approval was obtained from both institutions. One researcher from each university introduced the study and its objectives to psychology students during classes and announced invitations. All psychology students at both universities received an invitation email sent through student portals, containing a URL link to the study details and its questionnaire. The study was conducted via SurveyMonkey to ensure anonymity and easy access. In addition, a participant information sheet was included. It explained the study objectives and procedure, and participants' rights (voluntary participation, the right to withdraw at any stage). Data were collected in April 2016 (towards the end of the second academic term). On average, participants took about 20 minutes to complete the questionnaires. Study participants received no course credit nor any other form of compensation for their participation. 


\section{Measures}

\section{Demographic information}

Information on participants' age, gender, marital status, level of study, year of study, and Grade Point Average (GPA) was obtained through demographic questions.

\section{Academic performance}

Academic performance was measured by a five-point GPA system. Participants' were asked to report their GPA. This was the obtained GPA over all courses during the same semester in which the survey was administered.

\section{The Rosenberg Self-Esteem Scale}

The Arabic version of the Rosenberg Self-Esteem Scale (RSES) (Rosenberg, 1965), a widely used self-reported scale assessed participants' global self-esteem. The RSES consists of 10 items and is scored on a 4 point Likert scale ranging from $1=$ strongly agree to $4=$ strongly disagree. The scale contains 5 negative items, which must be reversed before calculating the total score. Total score ranges from 0 to 40, with 40 being the highest score. Higher total scores denote higher self-esteem. The RSES is a reliable and valid measure of global self-esteem (Gray-Little, Williams, \& Hancock, 1997; Silber \& Tippett, 1965), and has been widely used in Arabic-speaking samples (Abdel-Khalek, Korayem, \& El-Nayal, 2012; Zaidi, Awad, Mortada, Qasem, \& Kayal, 2015; Zayed et al., 2016). In the present study, the internal consistency reliability as determined by the Cronbach's alpha was $\alpha=.79$.

\section{The Academic Self-Efficacy Sub-Scale}

The Academic Self-Efficacy (ASE) subscale of the Patterns of Adaptive Learning Scales (PALS) was used to measure academic self-efficacy (perceptions of their competence to complete their class work) (Midgley et al., 2000). It consists of 5 items, rated on a 5-point Likert scale (where $1=$ not at all true and $5=$ very true). The authors reported a Cronbach's alpha coefficient of .78 (Midgley et al., 2000). The ASE has been used with tertiary students (Hsieh, Sullivan, \& Guerra, 2007) and is a valid and reliable measure (Dever \& Kim, 2016; Huang, 2016). Because there is no Arabic version of the ASE, the scale was translated into Arabic and back-translated into English. The final version was reviewed and approved by bi-lingual experts. In this study, the internal consistency reliability as determined by the Cronbach's alpha was $\alpha=$ .80 .

\section{The Perceived Stress Scale}

The Arabic version of the Perceived Stress Scale (PSS) was used to measure the levels of perceived stress (feelings and thoughts) experienced by 
the participants during the past month (Cohen, Kamarck, \& Mermelstein, 1983). The PSS consists of 10 items scored on 5-point Likert scale ranging from never (0) to almost always (4). The scale contains 4 positive items, which according to the developers, must be reversed before calculating the total score. Total score ranges from 0 to 40, with 40 being the highest score. Higher total scores indicate higher psychological stress. Total scores between $0-13$ are considered indicators of low perceived stress, 14-26 moderate perceived stress, and 27-40 high perceived stress. The original PSS has demonstrated acceptable levels of validity and reliability (Cohen \& Williamson, 1988; Sheldon Cohen \& Janicki-Deverts, 2012). Similarly, the Arabic version of the PSS has also been widely used (Almadi, Cathers, Mansour, \& Chow, 2012; Chaaya, Osman, Naassan, \& Mahfoud, 2010). In this study, Cronbach's alpha was $\alpha=.74$.

\section{The VARK Questionnaire}

The Arabic validated version of the VARK questionnaire, one of the most frequently used self-reported measures that assess learning styles, was used to investigate participants' preferred learning styles (Fleming \& Mills, 1992). This scale contains 16 items that identify four styles of learning by sensory preferences: V (Visual), A (Aural), R (Read/write), and $\mathrm{K}$ (Kinesthetic). Each item has four options, each option corresponds to a learning style, and participants can choose more than one option. According to the VARK guidelines, preferred learning style(s) can range from unimodal, bimodal, trimodal to multimodal learning style (Fleming \& Mills, 1992). The Arabic version of the VARK was found to be valid and reliable and has been extensively used with Arabic-speaking samples (Asiry, 2016; Stirling \& Alquraini, 2017).

\section{Data analysis}

Data analysis was conducted using IBM SPSS Statistics version 24.0 (IBM Corp, 2016). One of the requirements related to multiple regression is normality (Williams, Grajales, \& Kurkiewicz, 2013) and hence all quantitative variables were tested for normality using Kolmogorov-Smirnov and ShapiroWilk tests. All variables were found to be non-normally distributed in this dataset and hence we decided to use a more conservative non-parametric statistical process. These variables were represented by medians \pm Interquartile Range (IQR). Spearman's rho was applied to detect correlations between the variables. 


\section{Results:}

\section{Descriptive statistics}

Of the 290 invited participants, a total of 231 completed the questionnaires, of which 17 responses were discarded due to missing data. The study response rate was $79.6 \%$.

As the sample were from the male university campuses, all 214 participants were males. More than half of the study sample $(59.3 \%)$ was between the ages of 20-22 years. More than $95 \%$ of the sample were studying towards a Bachelor degree in psychology, and $4.2 \%$ were Masters degree students. Of those pursuing their Bachelor's degrees, over one-third were in the first year. Finally, most of the Masters level participants were in their first year. Demographic information of the study sample is presented in Table $\mathbf{1 .}$

Table 1. Demographic profile of study participants

\begin{tabular}{llll}
\hline Variables & & Frequency & Percent \% \\
\hline Age groups & 17-19 years & 15 & 7.0 \\
& 20-22 years & 127 & 59.3 \\
23-25 years & 61 & 28.5 \\
26-28 years & 3 & 1.4 \\
32-34 years & 8 & 3.7 \\
Gender & Males & 214 & 100 \\
Marital status & Females & 0 & 0 \\
& Married & 12 & 5.6 \\
Level \& Year of study & Single & 202 & 94.4 \\
& & & 95.8 \\
& Bachelor Degree & 205 & 38.3 \\
& First-year & 82 & 14 \\
& Second-year & 30 & 21.5 \\
& Third-year & 46 & 22 \\
& Fourth-year & 47 & 4.2 \\
\hline
\end{tabular}

Non-parametric (median $\pm \mathrm{IQR}$ ) measures were computed for GPA, ASE, RSES, PSS, and learning styles (see Table 2). Median GPA among study participants was 3.30 out of 5. For the ASE, total scores ranged between 5 and 25. For the RSES and the PSS, the range for the total scores was between 0 and 40. 
Table 2. Descriptive measures of quantitative variables

\begin{tabular}{ll}
\hline Variable & Median \pm IQR \\
\hline GPA & $3.30 \pm 0.77$ \\
ASE & $18 \pm 5$ \\
RSES & $22 \pm 4$ \\
PSS & $29 \pm 5$ \\
VARK modality & scores \\
Visual & $6 \pm 4$ \\
Auditory & $7 \pm 4$ \\
Reading/writing & $7 \pm 3$ \\
Kinaesthetic & $7 \pm 3$ \\
\hline
\end{tabular}

ASE = Academic Self-Efficacy subscale; RSES= Rosenberg Self-Esteem Scale; PSS= Perceived Stress Scale, IQR= Interquartile Range

\section{Stress rates and preferred learning styles}

The prevalence of stress among the sample was high. Based on participants' total scores on the PSS, 71\% were highly stressed and 29\% were moderately stressed. Median and IQR for the VARK scale are shown in Table 2. The majority of the study participants $(94 \%)$ were multimodal in their learning style.

\section{Correlations of self-esteem, academic self-efficacy, and perceived stress levels with GPA}

Academic performance was found to have low but significant correlations with academic self-efficacy, $\mathrm{r}_{\mathrm{s}}(212)=.188, \mathrm{p}=.003$, and selfesteem, $\mathrm{r}_{\mathrm{s}}(212)=.121, \mathrm{p}=.039$, meaning that an increase of academic selfefficacy or self-esteem would increase the GPA and vice versa. However, academic performance was not correlated with perceived stress levels. Table 3 displays Spearman's rank-order correlation coefficients between the variables.

Table 3. Correlation coefficients between academic performance and academic selfefficacy, self-esteem, and perceived stress

\begin{tabular}{|c|c|c|c|c|}
\hline & Spearman's rho & $\begin{array}{l}\text { Academic Self- } \\
\text { Efficacy }\end{array}$ & Self-Esteem & Perceived Stress \\
\hline \multirow{3}{*}{ GPA } & $\begin{array}{l}\text { Correlation } \\
\text { Coefficient }\end{array}$ & $0.188^{*}$ & $0.121^{* *}$ & -0.039 \\
\hline & Sig. (1-tailed) & 0.003 & 0.039 & 0.285 \\
\hline & $\mathrm{n}$ & 214 & 214 & 204 \\
\hline
\end{tabular}

\section{Discussion:}

The purpose of this study was to measure stress levels, assess preferred learning styles, and investigate the relationships between self-esteem, academic self-efficacy, perceived stress levels and academic performance 
among psychology students in Saudi Arabia. More than half of the sample reported high levels of stress and preferred a multimodal learning style. Selfesteem and academic self-efficacy had small but significant correlations with academic performance, but no correlation with perceived stress levels was found. These findings are consistent with previous research conducted in Saudi Arabia with medical and dental students and elsewhere, although this study has focused on a Saudi Arabian cohort not previously investigated.

The RSES-10 items (Rosenberg, 1965) had adequate internal consistency in the present study $(\alpha=.79)$, similar to studies conducted with a Saudi female sample (Zaidi et al., 2015). Self-esteem revealed a low but significant correlation with academic performance. This result is consistent with previous research (Booth \& Gerard, 2011; Edwards et al., 2010; Lane, Lane, \& Kyprianou, 2004; Pullmann \& Allik, 2008; Saadat, Ghasemzadeh, \& Soleimani, 2012). However, there appears to be gender differences, with studies often reporting higher levels of self-esteem in male participants than females (Hamaideh \& Hamdan-Mansour, 2014; Huang, 2010; Saadat et al., 2012). A recent large-scale cross-cultural study looked at age and gender differences in self-esteem $(n=985,937)$ across 48 nations and concluded that males consistently reported higher self-esteem than females (Bleidorn et al., 2016). Similar findings are reported in Arabic speaking nations (Abdel-Khalek et al., 2012). In the present study, our sample composition of male participants did not allow this gender difference to be explored.

The 5-item ASE subscale of the PALS had adequate internal consistency in this study $(\alpha=.802)$. In line with findings from previous research (Afari, Ward, \& Khine, 2012; Cayubit, 2014; Gore, 2006; Khan, 2013), academic self-efficacy was found to be significantly correlated with academic performance, however, the magnitude of this correlation was small. Researchers have investigated the association between academic achievement and academic self-efficacy, more specifically English discourse writing, and found a positive association (Adelodun \& Asiru, 2015), but other studies did not (Al-Mekhlafi, 2011). Positive correlations between self-efficacy and reading and meta-comprehension among non-native Arabic speakers have also been established (Ghraibeh, 2014). Moreover, although not tested in the present study, research suggests a gender gap in academic self-efficacy favoring males over females in some content domains such as physics (Cavallo, Potter, \& Rozman, 2004). In a meta-analysis, Huang (2013) explained that gender difference in academic self-efficacy is largely influenced by content domain and age.

In this study, these correlations were low but significant indicating that other variables will likely add value when exploring the relationships between self-esteem, academic self-efficacy and academic achievement. In future 
research, other factors such as, test anxiety, intrinsic value and so forth could be added to the variables of interest (Pintrich \& de Groof, 1990).

The PSS also had adequate internal consistency $(\alpha=74)$, similar to studies conducted with Jordanian samples (Almadi et al., 2012; Hattar-Pollara \& Dawani, 2006). Prevalence of stress in the present sample was high, with $71 \%$ of the sample being highly stressed. This is consistent with studies carried out in Saudi Arabia and Egypt on stress prevalence. For example, studies have reported high stress rates among medical and dental students (Abdel Rahman, Al Hashim, Al Hiji, \& Al-Abbad, 2013; Abdel Wahed \& Hassan, 2017; Abdulghani et al., 2014). Furthermore, no correlation was identified between academic performance and perceived stress levels in the present study. This finding is also consistent with results of Abdulghani (2008), Abdulghani and colleagues (2011), and Emmanuel et al. (2014), who also found no direct correlations between stress and academic performance. Other studies have found a negative but non-significant association between stress and academic achievement (Khan, Altaf, \& Kausar, 2013; Sohail, 2013).

In general, the findings of this study indicate that this group displays higher levels of stress compared to the general population, and furthermore aspects of grade achievement are associated with self-esteem, academic selfefficacy and perceived stress. Nonetheless, the group under investigation has two main dimensions associated with discipline (psychology students) and region (Saudi Arabia). Without specific control groups, the findings are unable to unpack the full implications associated with each dimension. However, these findings suggest that investigations of these dimensions would be worthwhile.

A limitation of this study is its cross-sectional design, where the relationship between the dependent and independent variables are examined at a single point of time. Second, this study employed a relatively small sample, which further limits the generalizability of findings. Our sample was drawn from only two universities in Saudi Arabia, where there are more than 30 universities. Future studies should attempt to recruit a larger representative sample of both females and males across the country. Moreover, a response bias is also possible, especially regarding the self-disclosed GPA; however, this may have been minimized by the anonymous nature of the study.

\section{Conclusion}

This study revealed high levels of stress among male psychology students. Consistent with previous research, results showed small but significant correlations between academic performance and self-esteem and self-efficacy and no correlation with perceived stress among psychology students in Saudi Arabia. Future research should explore the sources of stress and coping strategies among this group of students. Investigations into gender 
differences in relation to self-esteem, academic self-efficacy and stress are also warranted.

\section{Acknowledgment:}

This research did not receive any specific grant from any funding agencies.

\section{References:}

Abdallah, A., Al-zalabani, A., \& Alqabshawi, R. (2013). Preferred learning styles among prospective research methodology course students at Taibah University, Saudi Arabia. The Journal of the Egyptian Public Health Association, 88(1), 3-7.

Abdel Rahman, A. G., Al Hashim, B. N., Al Hiji, N. K., \& Al-Abbad, Z. (2013). Stress among medical Saudi students at college of medicine, King Faisal University. Journal of Preventive Medicine and Hygiene, 54(4), 195199.

Abdel Wahed, W. Y., \& Hassan, S. K. (2017). Prevalence and associated factors of stress, anxiety and depression among medical Fayoum University students. Alexandria Journal of Medicine, 53(1), 77-84.

Abdel-Khalek, A. M., Korayem, A. S., \& El-Nayal, M. A. (2012). Self-esteem among college students from four Arab countries. Psychological Reports, 110(1), 297-303.

Abdulghani, H. M., AlKanhal, A. A., Mahmoud, E. S., Ponnamperuma, G. G., $\&$ Alfaris, E. A. (2011). Stress and its effects on medical students: A crosssectional study at a college of medicine in Saudi Arabia. Journal of Health, Population, and Nutrition, 29(5), 516-522.

Abdulghani, H. M., Irshad, M., Al Zunitan, M. A., Al Sulihem, A. A., Al Dehaim, M. A., Al Esefir, W. A., ... Haque, S. (2014). Prevalence of stress in junior doctors during their internship training: A cross-sectional study of three Saudi medical colleges' hospitals. Neuropsychiatric Disease and Treatment, 10(1), 1879-1886.

Aboalshamat, K., Hou, X.-Y., \& Strodl, E. (2015). Psychological well-being status among medical and dental students in Makkah, Saudi Arabia: A crosssectional study. Medical Teacher, 37 Suppl 1, S75-81.

Adelodun, G. A., \& Asiru, A. B. (2015). Academic self-efficacy and gender as determinants of performance in English discourse writing among high achieving students in Ibadan, Oyo State. European Scientific Journal, 11(28), 308-318.

Afari, E., Ward, G., \& Khine, M. S. (2012). Global self-esteem and selfefficacy correlates: Relation of academic achievement and self-esteem among Emirati students. International Education Studies, 5(2), 49-57. 
Al-Harthy, I. S., \& Was, C. A. (2013). Knowledge Monitoring, Goal Orientations, Self-Efficacy, and Academic Performance: A Path Analysis. Journal of College Teaching \& Learning, 10(4), 263-278.

Almadi, T., Cathers, I., Mansour, A. M. H., \& Chow, C. M. (2012). An Arabic version of the Perceived Stress Scale: Translation and validation study. International Journal of Nursing Studies, 49(1), 84-89. https://doi.org/10.1016/j.ijnurstu.2011.07.012

Al-Mekhlafi, M. A. (2011). The relationship between writing self-efficacy beliefs and final examination scores in a writing course among a aroup of Arab EFL trainee-teachers. International Journal for Research in Education (IJRE), 29(1), 16-33.

Almigbal, T. H. (2015). Relationship between the learning style preferences of medical students and academic achievement. Saudi Medical Journal, 36(3), 349-355. https://doi.org/10.15537/smj.2015.3.10320

Al-Sowygh, Z. H. (2013). Academic distress, perceived stress and coping strategies among dental students in Saudi Arabia. The Saudi Dental Journal, 25(3), 97-105. https://doi.org/10.1016/j.sdentj.2013.05.002

Asiry, M. A. (2016). Learning styles of dental students. The Saudi Journal for Dental Research, 7(1), 13-17. https://doi.org/10.1016/j.sjdr.2015.02.002

Bandura, A. (1977). Self-efficacy: Toward a unifying theory of behavioral change. Psychological Review, 84(2), 191-215. https://doi.org/10.1037/0033295X.84.2.191

Bandura, A. (1991). Social cognitive theory of moral thought and action. In W. M. Kurtines \& J. L. Gewirtz (Eds.), Handbook of moral behavior and development (pp. 45-103). Hillsdale, NJ: Erlbaum.

Bleidorn, W., Arslan, R. C., Denissen, J. J. A., Rentfrow, P. J., Gebauer, J. E., Potter, J., \& Gosling, S. D. (2016). Age and gender differences in self-esteem: A cross-cultural window. Journal of Personality and Social Psychology, 111(3), 396-410. https://doi.org/10.1037/pspp0000078

Booth, M. Z., \& Gerard, J. M. (2011). Self-esteem and academic achievement: A comparative study of adolescent students in England and the United States. Compare: A Journal of Comparative and International Education, 41(5), 629648. https://doi.org/10.1080/03057925.2011.566688

Cardoso, A. P., Ferreira, M., Abrantes, J. L., Seabra, C., \& Costa, C. (2011). Personal and pedagogical interaction factors as determinants of academic achievement. Procedia - Social and Behavioral Sciences, 29, 1596-1605. https://doi.org/10.1016/j.sbspro.2011.11.402

Cavallo, A. M. L., Potter, W. H., \& Rozman, M. (2004). Gender differences in learning constructs, shifts in learning constructs, and their relationship to course achievement in a structured inquiry, yearlong college physics course for Life Science majors. School Science and Mathematics, 104(6), 288-300. https://doi.org/10.1111/j.1949-8594.2004.tb18000.x 
Cayubit, R. F. O. (2014). Academic self-efficacy and study hours as predictors of test anxiety among high school students. Philippine. 